\title{
Prevalence of Exclusive Breastfeeding and associated factors among young Women attending Mbarara Municipal Council Health Centre IV.
}

\author{
Allion Asiimire ${ }^{a, 1}$, Eve Katushabe ${ }^{a}$ \\ a Department of Nursing, Faculty of Nursing and Health Sciences, Bishop Stuart University, P.O. Box 09, Mbarara, \\ Uganda.
}

\begin{abstract}
\end{abstract}

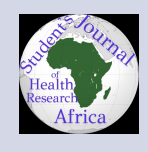

Background: ${ }^{a}$

Exclusive breastfeeding for six months provides the nurturing, nutrients and energy needed for physical and neurological growth and development. However, nearly 2 out of 3 infants are not exclusively breastfed for the recommended 6 months, a rate that has not improved in 2 decades In addition, efforts to increase EBF particularly in Uganda have stagnated, with rate remaining the same for many years. There is limited documented information specifically at Mbarara Municiple Council Health Centre IV (MMC H/C IV ) regarding prevalence of exclusive breast feeding and associated factors among young women. This study is therefore aimed at assessing the prevalence of exclusive breast feeding and associated factors among young women

Methodology:

A health Centre-based cross-sectional study was conducted among 93 pregnant women attending postnatal clinic at Mbarara municipal council health center IV. Information was collected using a structured question.

Results

The prevalence of exclusive breastfeeding was 31.2\%. The following variables were found to be significantly associated with exclusive breastfeeding, marital status OR 3.798 (Cl.381-8.484) $\mathrm{P}=0.045$, monthly income OR 2.750 (Cl.380-8.058) $p=0.033$

Conclusion and recommendations:

Low prevalence of exclusive breastfeeding was noted among young women attending Mbarara Municipal Council Health Centre IV. The factors associated with exclusive breast feeding include marital status and monthly income

\footnotetext{
${ }^{a}$ recieved: 14th/04/2021 accepted:

7th/05/2021 email: asiimireallion@gmail.com
}

\section{Background}

Globally, the rate of exclusive breastfeeding (EBF) was 43\% in 2015 (WHO, 2016). It is also estimated that only $38 \%$ of infants 0 to 6 months of age are exclusively breastfed worldwide (Senghore et al., 2018). In Sub-Saharan Africa and East Africa it was $31 \%$ and $42 \%$, respectively (WHO, 2016). Approxi- mately $22 \%$ of infant deaths could be prevented if mothers practiced EBF. (Manson et al., 2013: Joshi et al., 2014). In Uganda exclusive breastfeeding was estimated at 60\%. (kabwijamu, 2016).

Exclusive breastfeeding for six months provides the nurturing, nutrients and energy needed for physical and neurological growth and develop- 
ment. However, nearly 2 out of 3 infants are not exclusively breastfed for the recommended 6 months, a rate that has not improved in 2 decades (WHO/UNICEF 2018).

In low and middle income countries (LMIC including Uganda), where access to clean water, adequate sanitation, and basic health and social services are often limited, the effects of suboptimal breastfeeding are even more prominent (Ahmed et al., 2019). Lack of EBF is the most important risk factor for infant and young child morbidity and mortality including life-long impact like poor school performance, reduced productivity, and impaired intellectual development. (Tadesse et al., 2016)

The World Health Organization and the United Nations Children's Fund recommends early initiation of breastfeeding within the first hour of birth and exclusive breastfeeding (EBF) for the first 6 months of life, as well as continued breastfeeding until the child is 2 years of age (WHO/UNICEF 2009). Exclusively breastfed infants can only take oral rehydration solution, vitamins and minerals, and prescribed medications.(UNICEF, 2017).

The benefits of breastfeeding both to the mother and the baby are clearly documented (Black et al., 2008; Wambach \& Riordan, 2014; Rollins et al., 2016;). Research has shown that children who are breast feed have low risks of suffering from diarrheal diseases and other illnesses (Richard et al., 2018). Mothers who breastfeed their babies are able to bond with their infant, loss of the prepregnancy weight, child spacing by lactation amenorrhoea and their uterus contracts well (Kair, Flaherman, Flaherman, Newby, \&Colaizy, 2015).

Despite several interventions, the rate of EBF continues to be inadequate in developing countries (UNICEF 2008, Nkala et al., 2017). The aim of this study therefore is to determine the prevalence of exclusive breastfeeding and associated factors among young women attending Mbarara municipal council health centre IV.

Only six in 10 Ugandan children below the age of six months are exclusively breastfed. On average, $56 \%$ and $46 \%$ initiated breastfeeding in the first hour and practiced exclusive breastfeeding respectively. (Baale,2014). This is contrary to the best practice recommended by World Health Organization.In a study done at Mbarara regional referral hospitalexclusive breast feeding, was found at 49.8\%(Ampeire., 2008).
Early introduction of complementary feeding escalates the risk of diarrhea, malnutrition and death (WHO, 2012). The immediate consequence of poor feeding practices during 0-6 months of age leads to morbidity, mortality, and delayed mental and motor development. However, efforts to increase EBF particularly in Uganda have stagnated, with rate remaining the same for many years(UBOS and IMF, 2012). There is limited documented information specifically at MMC H/C IV regarding prevalence of exclusive breast feeding and associated factors among young women. This study is therefore aimed at assessing the prevalence of exclusive breast feeding and associated factors among young women.

\section{METHODS}

\section{Study design}

A Cross Sectional study design was carried out since data was collected at one point in time from a representative sample (Polit \& Beck, 2014).

\section{Study settings}

The study was carried out from Mbarara Municipal Council Health Centre IV. It is located in Mbarara district, approximately 265 kilometres by road southwest of Kampala, Western Uganda. MMC HC IV is a public health facility with a 10 bed capacity admitting only pregnant women that are sick or in labour. The catchment population is estimated at over 400,000 people (UBOS 2016).The majority of the women coming for ANC are from Mbarara district. As elsewhere in the country, a HC IV is manned by a medical officer and offers the following services: Immunization, Family planning, PMTCT, ART services, general OPD, Maternity and laboratory services. It has a theatre that only operates on minor surgeries like circumcision. The cadres of staff include the following: One medical officer, five clinical officers, one laboratory technologist, four laboratory technicians, one laboratory assistant, one anesthetic assistant, one dispenser, one public dental officer, one Senior nursing officer, five registered nurses, two registered midwives, one enrolled nurse, 08 enrolled midwives, two comprehensive enrolled nurses and ten support staff.

The Antenatal clinic operates on an outpatient basis offering services including: prenatal care, Health Education, routine counseling and testing 
for HIV and Tetanus Toxoid vaccination to pregnant women. However, the very sick pregnant women identified are transferred to the Maternity Ward for admission. According to the ANC clinic records the average attendance is 35 pregnant women (both new cases and re -attendance) per day from Monday to Friday excluding Thursday which is reserved for pregnant women that are HIV positive.

\section{Study population}

The study population included all women aged 1524 with children of 6 months and above attending family planning and postnatal clinics at Mbarara Municipal Council Health Centre IV during the time of data collection, who voluntarily agree to participate in the study.

\section{Sample size estimation}

Using Kish and Leslie's standard formula (1965), $\mathrm{N}=\mathrm{Z}^{2} \mathrm{PQ} / \mathrm{E}^{2}$.

Where $\mathrm{N}$ is the sample size,

Z-score responding to $95 \%$ of confidence interval which is 1.96,

$\mathrm{P}=$ percentage of respondents, estimated to be $50 \%$.

$\mathrm{Q}=1-\mathrm{P}=1-0.5=0.5$

$E=$ Level of error expected which is $5 \%(0.05)$

$\mathrm{N}=(1.96)^{2} \times 0.5(0.5) / 0.05^{2}$

$\mathrm{N}=384$

The study was adjusted for finite population,

Using Fisher's et al. (1998) formula;

$n f=n /(1+(n / N)$

Where; $\mathrm{nf}=$ desired sample for population $<10$ 000

$\mathrm{n}=$ calculated sample size for population $>10000$.

$\mathrm{N}=$ estimate of the population size (125)

$\mathrm{nf}=384 /(1+(384 / 125)$

$=384 / 4.072$

$\mathrm{nf}=94.3$ respondents; 95 respondents were considered.

\section{Sampling technique}

Women attending family planning and postnatal clinics were purposively selected to participate in the study.

\section{Inclusion criteria}

The study included all women aged 15-24 with children of 6 months and above attending family planning and postnatal clinics Mbarara Municipal Council Health Centre iv during the time of data collection.

\section{Exclusion criteria}

The study excluded women who were in much pain and those with mental issues like puerperal psychosis.

\section{Validity}

To ensure internal validity, the questionnaire was translated into Runyankole and back translation to English. In addition, the questionnaire was pretested on five women to address any ambiguities prior to the data collection process.

\section{Reliability.}

The researcher administered the questionnaire as this did not allow participants to discuss questions with other women. The researcher ensured that information got was relevant to exclusive breastfeeding and this helped in obtaining the correct responses. The questionnaire was short and clear for mothers to understand easily. The collected data was organized daily after a day's work

\section{Data Collection Procedure}

The researcher wrote down the responses. Data collection was carried out in a period of 14 days.

\section{Data analysis}

Data was analyzed using SPSS by establishing the relationship between the independent and dependent variables

\section{Data presentation}

Data was presented by use of variable tables which was put in representative graphs and piecharts, to ease the process of interpretation of findings.

\section{Ethical considerations}

The researcher obtained an introductory letter from the Head of Nursing Department to carry out research at the health facility. Permission was 
obtained from the Town Clerk Mbarara municipal council and MbararaMunicipal Council Health Centre iv management. Voluntary and informed consents were always sought from respondents and assured of confidentiality of the information provided.

\section{Dissemination of results}

The findings of the study were compiled into a report and three copies were produced and disseminated to the university library, Mbarara Municipal Council Health Centre IVand a copy for the Researcher.

\section{Results:}

\section{Participants' socio-demographic characteristics}

Table 1 summarizes the participants' social demographic characteristics. Of the 93 participants, $45.1 \%$ were aged $15-20,54.6 \%$ were aged $21-24$, $61.3 \%$ were married, $14.0 \%$ were single, 21.5 were divorced while $3.2 \%$ were widowed, and $61.3 \%$ were living in urban areas while $51.6 \%$ were earning less than 100,000 shillings. More than a third (39.8\%) were peasants and $48.4 \%$ had parity of two while $68.8 \%$ had their deliveries at health facilities. In addition to this $48.4 \%$ had studied up to secondary level.

\section{Prevalence of exclusive breastfeeding}

Figure below shows that $68.8 \%$ of the participants gave other foods to their babies other than breast milk while $31.2 \%$ did not give anything to their babies in the first six months after delivery.

\section{Bivariate analysis of factors associated with exclusive breast feeding.}

At bivariate analysis, Married women had a higher percentage (36.8\%) of exclusive breastfeeding as compared to single women (15.4\%), those divorced (20.0\%), and the widowed (33.3\%). More percentage $(42.9 \%)$ of none educated was able to exclusively breast feed compared to other levels, primary $26.1 \%$, secondary $33.3 \%$ and tertiary $27.8 \%$. Women who delivered from health facilities were more likely to exclusively breastfeed with a percentage of $42.2 \%$ as compared to those who delivered from home (4.2\%) and from a traditional birth attendant (20.0\%). In addition, being influenced by a health worker had a greater percentage (55.6\%) of exclusive breast feeding than being influenced by the partner (33.3\%), self (18.2\%) and partner (33.3\%). Mothers earning $<100,000$ were less likely to exclusively breast feed $(20.8 \%)$ compared to one's earning $110,000-250,000$ (30.4\%), $260,000-500,000$ (77.8\%) and >500,000 (38.5\%).

\section{Multivariate analysis of factors associated} with exclusive breastfeeding

Independent variables with $p<0.2$ at bivariate level were analyzed using multivariate logistic regression and then adjusted for age. Results showed that being married and the participants' monthly income were the only factors found to be significantly associated with exclusive breastfeeding. (aOR: 3.798 (0.381, 8.484), $\mathrm{p}=0.045$, aOR: 2.750 $(.380,8.058), p=0.033)$ respectively.

\section{Discussion}

\section{Prevalence of exclusive breast feeding}

The study revealed that the prevalence of exclusive breastfeeding was $31.2 \%$. This is consistent with the finding of world health organization (WHO) which reported the prevalence of exclusive breast feeding in East Africa to be $31 \%$ (WHO, 2016).

The current study's proportion of exclusive breast feeding is also accordant with a study done by Chekol et al., (2017) in south East of Ethiopia where $33 \%$ of the women attending postnatal clinic practiced exclusive breast feeding. The prevalence of exclusive breast feeding in this study is also relatively conformable with findings from a study by Setegn et al., (2012) in Bangladesh that revealed the proportion of mothers classified as practicing exclusive breast feeding to be $34.5 \%$. In addition, the results are similar to the Kenya national estimates of 32\%. (Okanda et al., 2014) This consonancy can be attributed to the similarity in the data collection tool, study design, cross-sectional design(Setegn et al., 2012; Mgongo et al., 2013; Cresswell et al., 2017) and to the fact that all these studies were health facility-based.

The results of this study are much lower than the findings in Goba District, Bale Zone 71.3\%, Jordan 
Table 1. $(\mathrm{N}=93)$

\begin{tabular}{|c|c|c|}
\hline Variable & Frequency & Percent (\%) \\
\hline \multicolumn{3}{|l|}{ Age } \\
\hline $15-20$ & 42 & 45.1 \\
\hline $21-24$ & 51 & 54.6 \\
\hline \multicolumn{3}{|l|}{ Status } \\
\hline Married & 57 & 61.3 \\
\hline Single & 13 & 14.0 \\
\hline Divorced & 20 & 21.5 \\
\hline Widowed & 3 & 3.2 \\
\hline \multicolumn{3}{|l|}{ Religion } \\
\hline Protestant & 28 & 30.1 \\
\hline Catholic & 37 & 39.8 \\
\hline Muslim & 13 & 14.0 \\
\hline Seventh day Adventist & 11 & 11.8 \\
\hline Others & 4 & 4.3 \\
\hline \multicolumn{3}{|l|}{ Education } \\
\hline None & 7 & 7.5 \\
\hline Primary & 23 & 24.7 \\
\hline Secondary & 45 & 48.4 \\
\hline Tertiary & 18 & 19.4 \\
\hline \multicolumn{3}{|l|}{ Occupation } \\
\hline Civil servant & 10 & 10.8 \\
\hline Business & 27 & 29.0 \\
\hline Peasant & 37 & 39.8 \\
\hline Housewife & 12 & 12.9 \\
\hline Others & 7 & 7.5 \\
\hline \multicolumn{3}{|l|}{ Residence } \\
\hline Urban & 57 & 61.3 \\
\hline Rural & 36 & 38.7 \\
\hline \multicolumn{3}{|l|}{ Birth Oder } \\
\hline 1 & 41 & 44.1 \\
\hline 2 & 45 & 48.4 \\
\hline 3 & 6 & 6.5 \\
\hline 4 & 1 & 1.1 \\
\hline \multicolumn{3}{|l|}{ Income } \\
\hline$<100,000$ & 48 & 51.6 \\
\hline $110000-250000$ & 23 & 24.7 \\
\hline $260000-500000$ & 9 & 9.7 \\
\hline$>500000$ & 13 & 14.0 \\
\hline \multicolumn{3}{|l|}{ Source of information } \\
\hline Radio & 47 & 50.5 \\
\hline Phone & 27 & 29.0 \\
\hline Television & 19 & 20.4 \\
\hline \multicolumn{3}{|l|}{ Why other feeds } \\
\hline MILK DID NOT COME & 35 & 37.6 \\
\hline LBW & 12 & 12.9 \\
\hline Advised by relatives & 7 & 7.5 \\
\hline Others & 14 & 15.1 \\
\hline \multicolumn{3}{|l|}{ Birth place } \\
\hline Home & 24 & 25.8 \\
\hline health facility & 64 & 68.8 \\
\hline TBA & 5 & 5.4 \\
\hline \multicolumn{3}{|l|}{ Type of delivery } \\
\hline Normal & 62 & 66.7 \\
\hline Cesarean & 31 & 33.4 \\
\hline
\end{tabular}


Table 2. Bivariate analysis of factors associated with exclusivebreast feeding

\begin{tabular}{|c|c|c|c|}
\hline Variable & $\begin{array}{l}\text { Exclusive } \\
\text { feeding } \\
\text { NO (\%) }\end{array}$ & $\begin{array}{c}\text { breast } \\
\text { YES (\%) }\end{array}$ & $P$ value \\
\hline \multicolumn{4}{|l|}{ Age } \\
\hline $15-20$ & $38(74.5)$ & $13(25.5)$ & .093 \\
\hline $21-24$ & $26(61.9)$ & $16(38.1)$ & \\
\hline \multicolumn{4}{|l|}{ Status } \\
\hline Married & $35(61.4)$ & $22(36.8)$ & .043 \\
\hline Single & $11(84.6)$ & $2(15.4)$ & \\
\hline Divorced & $16(80.0)$ & $4(20.0)$ & \\
\hline Widowed & $2(66.7)$ & 1(33.3) & \\
\hline \multicolumn{4}{|l|}{ Religion } \\
\hline Protestant & $22(78.6)$ & $6(21.4)$ & \\
\hline Catholic & $22(59.5)$ & $15(40.5)$ & 0.695 \\
\hline Muslim & $11(84.6)$ & $2(15.4)$ & \\
\hline Seventh day Adventist & $8(72.7)$ & $3(27.3)$ & \\
\hline Others & $1(25.0)$ & $3(75.0)$ & \\
\hline \multicolumn{4}{|l|}{ Education } \\
\hline None & $4(57.1)$ & $3(42.9)$ & \\
\hline Primary & $17(73.9)$ & $6(26.1)$ & .007 \\
\hline Secondary & $30(66.7)$ & 15 (33.3) & \\
\hline Tertiary & $13(72.2)$ & $5(27.8)$ & \\
\hline \multicolumn{4}{|l|}{ Occupation } \\
\hline Civil servant & $6(60.0)$ & $4(40.0)$ & .310 \\
\hline Business & $19(70.4)$ & $8(29.6)$ & \\
\hline Peasant & $28(75.7)$ & $9(24.3)$ & \\
\hline Housewife & $6(50.0)$ & $6(50.0)$ & \\
\hline Others & 5 (71.4) & $2(28.6)$ & \\
\hline \multicolumn{4}{|l|}{ Residence } \\
\hline Urban & $40(70.2)$ & $17(29.8)$ & 0.324 \\
\hline Rural & $24(68.6)$ & $11(31.4)$ & \\
\hline \multicolumn{4}{|l|}{ Birth Oder } \\
\hline 1 & $30(73.2)$ & $11(26.8)$ & \\
\hline 2 & $29(64.4)$ & $16(35.6)$ & 0.746 \\
\hline 3 & $4(66.7)$ & $2(33.3)$ & \\
\hline 4 & $1(100)$ & $0(0)$ & \\
\hline \multicolumn{4}{|l|}{ Place of delivery } \\
\hline Home & 23(95.8) & $1(4.2)$ & \\
\hline health facility & $37(57.8)$ & $27(42.2)$ & .002 \\
\hline TBA & $4(80.0)$ & $1(20.0)$ & \\
\hline \multicolumn{4}{|l|}{ Type of delivery } \\
\hline Normal & $44(66.7)$ & $17(33.3)$ & .335 \\
\hline Cesarean & 19(63.3) & $11(36.7)$ & \\
\hline \multicolumn{4}{|l|}{ Mother/infant issue } \\
\hline Milk did not come & $34(97.1)$ & $1(2.9)$ & \\
\hline LBW & $9(75.0)$ & $3(25.5)$ & .320 \\
\hline Advised by relatives & $7(100)$ & $0(0)$ & \\
\hline Others & $14(100)$ & $0(0)$ & \\
\hline \multicolumn{4}{|l|}{ Health problem } \\
\hline maternal illness & $24(96.0)$ & $1(4.0)$ & \\
\hline infant illness & $14(87.5)$ & $2(12.5)$ & \\
\hline Others & $4(100)$ & $0(0)$ & .621 \\
\hline None & $22(95.6)$ & $1(4.4)$ & \\
\hline \multicolumn{4}{|l|}{ Influential person } \\
\hline Partner & $10(66.7)$ & $5(33.3)$ & \\
\hline
\end{tabular}




\section{prevalence}

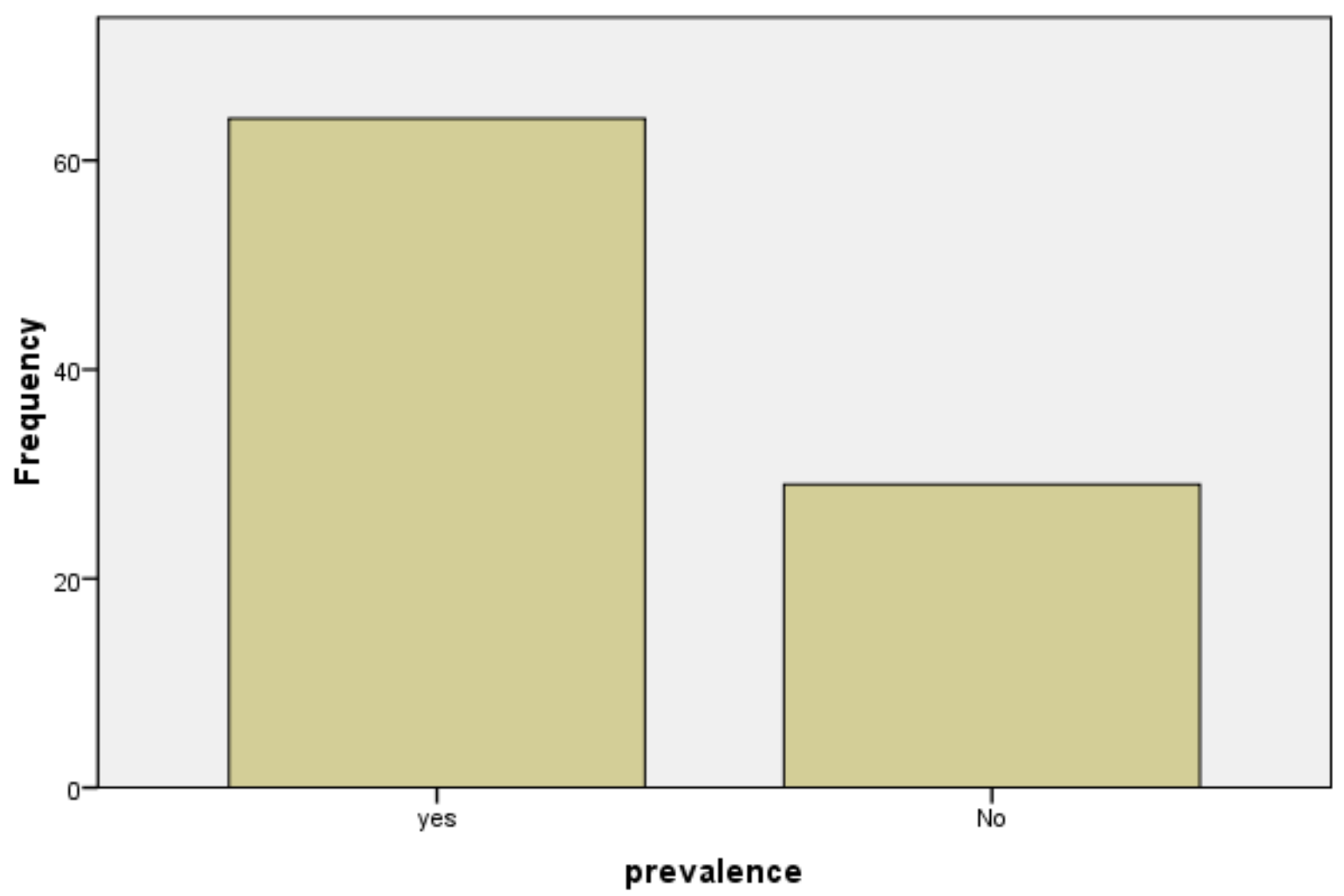

Figure 1. Prevalence of exclusive breastfeeding

Table 3. Multivariate analysis of factors associated with exclusive breastfeeding

\begin{tabular}{lll}
\hline $\begin{array}{l}\text { Variable } \\
\text { Age }\end{array}$ & aOR $((95 \% \mathrm{Cl}))$ & P value \\
$15-20$ & 1 & 0.802 \\
$21-25$ & $1.676(.502-5.590)$ & \\
$\begin{array}{l}\text { Status } \\
\text { Married }\end{array}$ & $3.798(.381-8.484)$ & $0.045^{*}$ \\
Not married & 1 & \\
$\begin{array}{l}\text { Education } \\
\text { None formal }\end{array}$ & 1 & \\
$\begin{array}{l}\text { Formal } \\
\text { Birthplace } \\
\text { Home }\end{array}$ & $1.546(0.516,12.568)$ & 0.251 \\
health facility & $1.498(.091-2.736)$ & 0.589 \\
Income & & \\
$<100,000$ & 1 & $0.033^{*}$ \\
\hline 100,000 & $2.750(.380-8.058)$ & \\
\hline
\end{tabular}


(77\%), Madagascar, (70\%), Zambia, (74\%), Ghana, (79\%) and Bolivia (65\%). Amhara Region, (81\%), Oromia Region, (62\%) and South Nations and Nationalities Peoples Region (64\%). In addition, higher prevalence of exclusive breast feeding was reported in other numerous studies such as $49.8 \%$ at Mbarara Regional Referal Hospital (Ampeire IP 2008), $46 \%$ in Uganda ( Baale), 44\% among employed women in north-western Uganda (Seid, et al., 2013) 50\% in Ethiopia (chekol, et al., 2017), 58\% in Brazil (Setegn, et al., 2012). The methodological differences between studies might attribute to the difference in the prevalence of exclusive breast feeding among these countries.

However, lower prevalence of exclusive breast feeding as compared to results of this study, was reported in other numerous studies such as $20.7 \%$ in Kilimanjaro (Mgongo, et al., 2013), 24.4\% AlHussaSauda Arabia (Gilan, et al., 2011), 13.8\% in Canada (Al-Sahab et al., 2010) and 24\% in Myanmer. The socio demographic factors including marital status might attribute for the difference in breastfeeding practices between this study and studies from other countries. The difference in study designs used in other studies could also be a reason for this.

\section{Factors associated with exclusive breastfeeding}

In this study, mothers who were earning highly (>100,000Ugs) were positively associated with exclusive breastfeeding ( $O R=2.750)$. This is similar with the results reported in studies by Tan, 2011 and Prakash et al., (2014), who found that mothers with high household income had higher odds of exclusive breastfeeding compared to mothers with low household income. Furthermore, studies by Okeh et al., (2010); Ekanem, et al., (2012); Ajibade, Okunlade et al., (2013) revealed that high socioeconomic status was significantly related to high exclusive breastfeeding rate, and long duration of overall breastfeeding. This is because mothers with high income are able to afford to balance diet meal rich in foods which support breast milk production and thus have enough breast milk for their infants. Many other scholars have posited that maternal employment is in a continuous competition with breastfeeding (Okeh, 2010). However, the result contradict with a study by Setegn et al., (2012), which revealed that mothers who were earning less had a significant association with a exclusive breastfeeding. This was because of the fact that less maternity leave, which makes employed mothers have less opportunity to stay at home, compromising exclusive breastfeeding. Mothers also may have to leave their babies to search for a job.

Married women had significantly higher odds of EBF (OR=3.79) compared to unmarried women. This is in line with a study by Mgongo et al., (2013) which showed that women living with their partners were more likely to exclusively breastfeed their infants. This could be due to the fact that unmarried women lack social support to continue practicing EBF as they have to earn for the family. Additionally, in other studies, sub optimal infant feeding was common with single mothers ( Tampah-Naah et al., 2013). Studies concluded that single mothers are less likely to exclusively breastfeed adequately and longer due to absence of partners' support and confidence compared with married mothers.

\section{Conclusion:}

Low prevalence of exclusive breastfeeding was noted among young women attending Mbarara Municipal Council Health Centre IV. The factors associated with exclusive breast feeding include marital status and monthly income.

\section{Recommendations :}

Given the low prevalence of exclusive breastfeeding, I recommend:

- Improved quality of service delivery in regard to breastfeeding practices

- Integration of exclusive breast feeding services with existing maternal health care among public health centers

- Continued promotion of partner involvement in maternal health especially after delivery should also be emphasized as this can bridge the existing chasm.

- Lastly, more research is recommended especially a community based study may can be pursued to determine the magnitude of exclusive breastfeeding in the community as this study might have underestimated the prevalence since it was health centre-based.

\section{Area for further research}

Impact of health workers on breastfeeding practices 


\section{Limitations:}

The findings may not be generalizable to the entire breast feeding women in the community since not all of them seek care from the government facility.

Additionally, the study was facility-based so it may not be representative of the entire community since not all people in that area visit the health facility.

\section{Operational definitions}

Factors: refers to anything that affects life events either positively or negatively.

Exclusive breast feeding; refers to the infant feeding method whereby mothers feed their infants with only breast milk for the first six months of life without any other supplement not even water except for prescribed drugs and vitamins.

HIV: this is an infection that affects the body's immune system by infecting helper T-cells causing immune suppression.

Sub-optimal breast feeding refers to inability to adhere to standard recommendations like initiation of breastfeeding within one hour, giving colostrums and breastfeeding for six months plus breast feeding up to 2 years.

Prevalence: This is the proportion of cases in the population at a given time. It is the measurement of all individuals affected by the disease at a particular time .
Abbreviations
HIV: Human Immune Virus
SSA: Sub Saharan Africa
EBF: Exclusive Breast feeding
WHO: World Health Organization
UNICEF: United Nations Children's Fund
WLWH: Women living with HIV
KAP: Knowledge attitude and practices
H/C IV : Mbarara Municiple Council Health Centre IV

\section{Acknowledgments:}

First and foremost, the entire honor goes to God the Almighty for the guidance, strength, power of mind, protection and for giving me a healthy life to undertake this research study

My sincere gratitude goes to my supervisor, Sr. Eve Katushabe for being a source of inspiration, a role model and a pillar of my academic excellence.
Heartfelt appreciations to my colleagues Ampumuza Anna, Mr Agaba Dickson, Mr. Natwijuka Andrew, and the entire class of 2016 for the support, encouragement and credible ideas that have greatly contributed to the accomplishment of this dissertation and course at large.

\section{A References:}

1) Ahmed, K.Y., Page, A., Arora, A. et al. Trends and determinants of early initiation of breastfeeding and exclusive breastfeeding in Ethiopia from 2000 to 2016. Int Breastfeed J 14, 40 (2019). https://do i.org/10.1186/s13006-019-0234-9 PMid:31528197 PMCid:PMC6740001

2) Ajibade, B., Okunlade, J., Makinde, O., Amoo, P. \&Adeyemo, M. 2013.Factors influencing the practice of exclusive breastfeeding in rural communities of Osunstate, Nigeria. European Journal of Business and Management.

3) Al-sahab,B., Lanes,A., Feldman,M., \&Tamim,H. (2010). Prevalence and predictors of 6-month exclusive breastfeeding among Canadian women: A national survey. BMC Pediatrics. https://doi.o rg/10.1186/1471-2431-10-20 PMid:20377899 PMCid:PMC2858135

4) Ampeire IP. (2008). Perception and knowledge on exclusive breast feeding among wonen attending antenatal and post natal clinics. A study from Mbarara hospital -Uganda.DarEs Salaam Medical Students' Journal.

5) Black, R. E., Allen, L. H., Bhutta, Z. A., Caulfield, L. E., de Onis, M., \&Ezzati, M.(2008). Maternal and child undernutrition: Global and regional exposures and health consequences. Breastfeeding Medicine, https://doi.org/10.1016/S0140-6736(07) 61690-0

6) Chekol,DA., Biks, GA., Gelaw,YA., Melsew,YA. (2017). Exclusive breastfeeding an mothers' employment status in Gondar town, Northwest Ethiopia: a comparative cross-sectional study. Int Breastfeed J https://doi.org/10.1186/s13006-017-0 118-9 PMid:28638435 PMCid:PMC5473972

7) Cresswell JA, Ganaba R, Sarrassat $S$, Cousens S, SomeÂ H, Diallo AH, et al. (2017) Predictors of exclusive breastfeeding and consumption of soft, semi-solid or solid food among infants in Boucle du Mouhoun, Burkina Faso: A cross-sectional survey. PLoS ONE 12 https://doi.org/10.1371/journal.pone. 0179593 PMid:28640900 PMCid:PMC5480894 
8) Edward Bbaale. (2014). Determinants of Early Initiation, Exclusiveness and Duration of Breastfeeding in Uganda.HEALTH POPUL NUTR INTERNATIONAL CENTRE FOR DIARRHOEAL DISEASE RESEARCH.

9) Ekanem, I., Ekanem, A., Asuquo, A. \&Eyo, V. 2012. Attitude of working mothers to exclusive breastfeeding in Calabar municipality, Cross River State, Nigeria. Journal of Food Research. 1( https:// doi.org/10.5539/jfr.v1n2p71

10) John O Okanda, Craig B Borkowf, Sonali Girde, Timothy K Thomas and Shirley Lee Lecher (2014) Exclusive breastfeeding among women taking HAART for PMTCT of HIV-1 in the Kisumu Breastfeeding Study BMC Pediatrics https://doi.org/10.1186/1471 -2431-14-280 PMid:25380718 PMCid:PMC4326202

11) Kair, L. R., Flaherman, V. J., Newby, K. A., \&Colaizy, T. T. (2015). The experience of breastfeeding the late preterm infant: A qualitative study. https:// doi.org/10.1089/bfm.2014.0121 PMid:25647732

12) Lydia Kabwijamu, Peter Waiswa, Vincent Kawooya, Christine K. Nalwadda,Martin K Mutua, Tabither M Gitau3 and Nelly Yatich (2011) Patterns and determinants of breastfeeding and complementary feeding practices in urban informal settlements, Nairobi Kenya, BMC Public Health.

13) Mgongo, M., Mosha, M. V., Uriyo, J. G., Msuya, S. E., \& Straypedersen, B. (2013). Prevalence and predictors of exclusive breastfeeding among women in Kilimanjaro region, Northern Tanzania: A population based cross-sectional study. International Breastfeeding Journal, https://doi. org/10.1186/1746-4358-8-12 PMid:24107593 PMCid:PMC3852397

14) Nkala, TE.,Msuya, SE. (2011). Prevalence and predictors of exclusive breastfeeding among women in Kigoma region Western Tanzania: a community based cross sectional study. Int Breastfeed J. https://doi.org/10.1186/1746-4358-617 PMid:22070861 PMCid:PMC3221641

15) Okeh, U.M. (2010). Breastfeeding and the mother-child relationship: A case study of Ebonyi State University Teaching Hospital, Abakaliki. African Journal of Primary Health Care \& Family Medicine. https://doi.org/10.4102/phcfm.v2i1.97

17) Prakash Chandra Joshi, Mirak Raj Angdembe, Sumon Kumar Das, Shahnawaz Ahmed, Raffle, H., Ware, L.J., Borchardt, A.R. \& Strickland, H.A. (2011). Factors that influence breastfeeding initiation and persistence in Ohio's Appalachian region. Ohio:
Voinovich School of leadership and public affairs at Ohio.

18) Richard, S. A., McCormick, B. J. J., Seidman, J. C., Rasmussen, Z., Kosek, M. N., Rogawski, E. T., ... On Behalf Of The Mal-Ed Network Investigators (2018). Relationships among common illness symptoms and the protective effect of breastfeeding in early childhood in MALED: An eight-country cohort study. The American Journal of TropicalMedicine and Hygiene. https://doi.org/10.4269/ajtmh.17-04 57 PMid:29380724 PMCid:PMC5930868

19) Rollins, N. C., Bhandari, N., Hajeebhoy, N., Horton, S., Lutter, C. K., Martines, J. C. (2016). Why invest and what it will take to improve breastfeeding practices? The Lancet. https://doi.org/10.1016/ S0140-6736(15)01044-2

20) Seid, et al. (2013). Prevalence of Exclusive Breast feeding Practices and associated factors among mothers in Bahir Dar city, Northwest Ethiopia: a community based cross-sectional study. Int Breastfeeding J. https://doi.org/10.1186/1746-4 358-8-14 PMid:24152996 PMCid:PMC3815630

21) Setegn. (2012). Factors associated with exclusive breastfeeding practices among mothers in Goba district, south east Ethiopia: a cross-sectional study. Int Breastfeed J. https://doi.org/10.1186/174 6-4358-7-17 PMid:23186223 PMCid:PMC3560275

22) Sika-Bright, S. 2010. Socio-cultural factors influencing infant feeding practices of mothers attending welfare clinic in Cape Coast, Ghana. Department of Sociology and Anthropology, University of Cape Coast.

23) Tampah-Naah, AM., \& Kumi-Kyereme. 2013. Determinants of exclusive breastfeeding among mothers in Ghana: a crosssectional study. International Breastfeeding Journal. https://doi. org/10.1186/1746-4358-8-13 PMid:24119727 PMCid:PMC3852847

24) Tesfaye Setegn, Tefera Belachew, Mulusew Gerbaba, Kebede Deribe, Amare Deribew and Sibhatu Biadgilign.(2012) Factors associated with exclusive breastfeeding practices among mothers in Goba district, south east Ethiopia: a cross-sectional study International Breastfeeding Journal. https:/ /doi.org/10.1186/1746-4358-7-17 PMid:23186223 PMCid:PMC3560275

25) Thomas Senghore, Tobiloba Alex Omotosho, Omar Ceesay and Daisy Clara H. Williams (2018) Predictors of exclusive breastfeeding knowledge and intention to or practice of exclusive breastfeeding among antenatal and postnatal women 
receiving routine care: a cross-sectional study, International Breastfeeding Journalhttps://doi.org/ 10.1186/s13006-018-0154-0 PMid:29507600 PMCid:PMC5833059

26) UNICEF (2017)UNICEF-NutritionBreastfeeding. Retrieved from https://www.u nicef. org/nutrition/index_24824.html.

27) United Nations Children's Fund (UNICEF). The State of the World's Children 2008: Child Survival. United Nations Children's Fund, New York

28) Wambach, K., \& Riordan, J. (2014). Breastfeeding and human lactation. Burlington, MA: Jones \& Bartlett Publishers.

29) Wasser H, Bentley M, Borja J, Davis GB, Thompson A, \&Slining M, Adair L. (2011). Infants perceived as "fussy" are more likely to receive complementary foods before 4 months. Pediatrics https://doi.org/10.1542/peds.2010-016 6 PMid:21220398 PMCid:PMC3025423

30) WHO Media Centre Fact Sheet.Infant and young child feeding.World Health Organization, (2016)

31) World Health Organization (2009) Infant and young child feeding (IYCF) model chapter for textbooks for medical students and allied health professionals.

\footnotetext{
${ }^{1}$ recieved: 13th/04/2021 accepted: 7th/05/2021 email: asiimireallion@gmail.com
} 